\title{
Estudo das variações da massa específica em Pinus oocarpa através da técnica de atenuação da radiação gama
}

\author{
Marcos Antonio de Rezende ${ }^{(1)}$ \\ Elias Taylor Durgante SeVero ${ }^{(2)}$ \\ Isabel Royuela Quintana ${ }^{(3)}$
}

\section{RESUMO}

O trabalho enfatiza as vantagens em se usar técnica da radiação gama no estudo das propriedades físicas da madeira, evidenciando o uso do Amerício-241. Com essa técnica foram estudados os anéis de crescimento de sete árvores de Pinus oocarpa aos 24 anos, fundamentado nas variações de sua massa específica como indicativos de qualidade da madeira para fins industriais e energéticos. Os resultados mostraram que a maioria das árvores apresentaram um pico de alta massa específica no início do crescimento, seguida de um decréscimo até a idade de 4 anos. A partir dessa idade, houve um acréscimo gradual da massa específica até a idade de corte, efetuada aos 24 anos. Observou-se ainda uma grande variabilidade entre a massa específica do lenho inicial e tardio durante todo período de crescimento destas árvores. Os valores encontrados para a média da massa específica, em $\mathrm{g} / \mathrm{cm}^{3}$, do Pinus oocarpa, nas posições relativas à altura comercial da árvore (base, $25 \%, 50 \%$ e $75 \%$ ), foram respectivamente de: 0,$58 ; 0,56 ; 0,52$ e 0,53 , evidenciando um decréscimo da massa específica no sentido base-topo das árvores.

Palavras- chave: Pinus oocarpa, idade, radiação gama, massa específica.

\section{ABSTRACT}

Specific mass variations study in Pinus oocarpa by the gamma radiation lessening technique. The work emphasizes the advantages in using nuclear energy as the gamma radiation technique in the studies of the physical

\footnotetext{
${ }^{1}$ Físico Dr., Professor Adjunto do Departamento de Física e Biofísica- Universidade Estadual Paulista, Botucatu (SP)

${ }^{2}$ Engenheiro Florestal, Dr., Professor Doutor do Departamento de Recursos Naturais, Universidade Estadual Paulista, CEP 18.603-970, Botucatu (SP).

${ }^{3}$ Ingeniera Forestal, Bel. Escuela Superior de Ingenierías Agrarias, Universidad de Valldolid, Espanha.
} 
properties of the wood, evidencing the use of the ${ }^{241} \mathrm{Am}$, as gamma radiation source. Through that technique, the annual rings of seven Pinus oocarpa were analyzed, being studied the variations of the specific mass as a factor of quality. The results showed that the most of the trees of Pinus oocarpa presented a pick of high specific mass in the beginning of the growth, followed by a decrease on the 4 year-old. Starting from that age, there was gradual increment of the specific mass to the cut age, made to the 24 years. The values find to the average specific mass, $\mathrm{g} / \mathrm{cm}^{3}$, in the commercial height (base, $25 \%, 50 \%$ e $75 \%$ ) were respectively 0,$58 ; 0,56 ; 0,52$ e 0,53 , showing a decrease in the specific mass (base-top direction) of the trees.

Key words: Pinus oocarpa, age, gamma radiation, specific mass.

\section{INTRODUÇÃO}

Uma árvore, ao longo de sua vida, armazena em seus anéis várias informações ambientais importantes. As modificações do clima e do solo são registradas pelas árvores, causando curiosas modificações na estrutura física e química dos anéis de crescimento. Assim, as geadas, períodos secos ou chuvosos, incêndios, ventos dominantes, poluição do ar atmosférico e da água, poluição radioativa podem ser dimensionadas pela leitura dos anéis de crescimento.

A tarefa mais difícil está na leitura dessas informações que requerem uma variedade de metodologias desde algumas bem simples até outras altamente sofisticadas.

Existem vários métodos para determinação da massa específica da madeira, dos quais pode-se citar desde os mais simples tais como: medidas diretas de massa e volume através de balança e paquímetro de precisão, imersão em água ou mercúrio, até outros mais sofisticados como os métodos nucleares utilizando um feixe de radiação gama, partícula beta ou raios-X (FERRAZ et al., 1982; SEVERO, 1998). Quando o interesse é apenas a obtenção do valor médio da massa específica da amostra, os métodos tradicionais mais simples geralmente podem ser utilizados até com certa vantagem em relação aos métodos nucleares. Entretanto, quando se deseja maiores detalhes ao longo da amostra, ou seja, medidas pontuais ou milimétricas para a massa específica, é necessária, então, a utilização dos métodos nucleares.

Os métodos de determinação da massa específica de madeira pelo uso dos raios-X ou partículas beta, apesar de apresentarem boa precisão, têm aplicação limitada pela espessura da amostra. Para que haja sensibilidade nas determinações, a espessura média das amostras não deve exceder a $1,0 \mathrm{~cm}$ para raios-X e $2,0 \mathrm{~cm}$ para a beta do ${ }^{90} \mathrm{Sr}$. Em várias situações, no entanto, é necessário trabalhar-se com amostras mais espessas. Nesses casos, o uso da 
radiação gama tem-se mostrado adequado permitindo trabalhar com amostras variando de 1,0 até $40,0 \mathrm{~cm}$ de espessura.

No Brasil, o uso da radiação gama para determinação da massa específica da madeira surgiu na década de 70, a partir dos trabalhos desenvolvidos no Centro de Energia Nuclear na Agricultura, entre os quais pode-se citar FERRAZ (1976). Neste trabalho, o autor descreve com detalhes a utilização da radiação gama do ${ }^{241} \mathrm{Am}$ (com fotopicos de 59,6; 26,4 e 32,2 $\mathrm{Kev}$ ), e relata ainda as vantagens dessa fonte radioativa, ressaltando a faixa de energia adequada e facilidade de blindagem da radiação. A partir daí, surgiram vários trabalhos nessa área incluindo teses de mestrado e de doutorado (TROVATTI, 1982; REZENDE 1987;1997)

O trabalho em questão enfatiza o uso da técnica de atenuação da radiação gama do Amerício-241 $\left({ }^{241} \mathrm{Am}\right)$ na área de Ciências Florestais. Com esta técnica se estuda a madeira de forma pontual. Assim foram estudadas o comportamento da massa específica no sentido radial (medula-casca) e longitudinal (base-topo), como parâmetro indicativo de qualidade da madeira de Pinus oocarpa.

\section{MATERIAL E MÉTODOS}

\section{$\underline{\text { Amostragem }}$}

Para estudar as variações da massa específica na árvore e no povoamento foram selecionadas 7 árvores de Pinus oocarpa na idade de 24 anos. As amostras selecionadas foram coletadas na Fazenda Monte Alegre próxima à cidade de Agudos - SP, à $22^{\circ} 25^{\prime}$ Sul de latitude e $49^{\circ} 00^{\prime}$ Oeste de longitude, em povoamento da Empresa Duraflora S.A. A precipitação anual da região nos últimos 24 anos foi de aproximadamente $1.420 \mathrm{~mm}$ e a altitude do local é de $550 \mathrm{~m}$. O tipo de solo predominante na região é o latossolo vermelho amarelo fase arenosa. As árvores foram escolhidas de tal forma que representassem o povoamento em termos de incrementos médios anuais de volume. O potencial de crescimento da espécie foi de $26,7 \mathrm{~m}$ para altura e 41,9 $\mathrm{cm}$ para diâmetro. Para cada árvore, foram retiradas 4 amostras em forma de cilindros com $10 \mathrm{~cm}$ de altura, nas seguintes posições, de acordo com a altura comercial: da base, a $25 \%$ da altura comercial, a $50 \%$ da altura comercial e a $75 \%$ da altura comercial; correspondendo respectivamente às posições 1, 2, $3 \mathrm{e}$ 4.

\section{Preparo dos discos para análise}

Os discos foram inicialmente secos ao ar para perderem as maiores parcelas de umidade e de resina até que atingissem massa constante, numa 
umidade de $15 \%$. Em seguida os mesmos foram aplainados e lixados até adquirir uma espessura uniforme em torno de $2,0 \mathrm{~cm}$. Posteriormente, foram mantidos em laboratório em câmara climatizada com umidade relativa e temperaturas constantes de tal forma que os mesmos adquirissem uma umidade de equilíbrio de aproximadamente $12 \%$. Nestas condições, efetuou-se a análise da massa específica do material

\section{$\underline{\text { Medidas da massa específica }}$}

O método utilizado para determinação da massa específica foi o de atenuação da radiação gama do ${ }^{241}$ Am proposto por FERRAZ (1976). A massa específica da madeira foi determinada pela equação (1), adaptada da Lei de Beer-Lambert, com as correções previstas devido ao tempo morto do sistema eletrônico através das equações (2) e (3).

$$
\begin{aligned}
& \rho_{12}=\frac{\ln \left(I_{O C}-B G\right)-\ln \left(I_{C}-B G\right)}{\mu_{m} \cdot \chi_{m}} \\
& I_{O C}=\frac{I_{0}}{1-\tau I_{0}} \\
& I_{C}=\frac{I}{1-\tau I}
\end{aligned}
$$

Sendo:

$\rho_{12}=$ massa específica da madeira na umidade de equilíbrio em 12\%;

$\mu_{m}=\quad$ coeficiente de atenuação de massa, da madeira na umidade de $12 \%$ $\mathrm{em} \mathrm{cm} / \mathrm{g}$;

$\chi_{m}=$ espessura da madeira em $\mathrm{cm}$, na umidade de $12 \%$;

$B G=\quad$ radiação de fundo em contagens por minuto;

$I_{0}=$ taxa de contagem (contagens por minuto) obtida experimentalmente sem o material absorvedor;

$I=\quad$ taxa de contagem (contagens por minuto) obtida experimentalmente após passagem através do absorvedor ou da madeira;

$I_{O C}=$ valor de $I_{0}$ corrigido devido ao tempo morto do sistema eletrônico através da equação (2); 
$I_{C}=$ valor de $I$ corrigido devido ao tempo morto do sistema eletrônico através da equação (3);

$\tau=$ tempo morto do sistema eletrônico $\left(1,0 \times 10^{-7}\right.$ minutos $)$.

\section{$\underline{\text { Transformacão da massa específica a } 12 \% \text { em massa específica a } 0 \%}$}

Através da equação (1) foi possível determinar a massa da madeira de milímetro em milímetro, ao longo do raio. Os cálculos da massa específica em função da idade, foram obtidos através da análise dos anéis de crescimento da madeira, efetuando-se médias ponderadas em cada anel anual, conforme procedimento adotado por REZENDE et al. (1995). .Para conversão da massa especifica a $12 \%$ em massa específica a $0 \%$, utilizou-se a equação 4 proposta por REZENDE (1997).

$$
\rho_{o}=\frac{1,104-\sqrt{1,219-0,268 \rho_{12}}}{0,134}
$$

Sendo:

$\rho_{\mathrm{o}}=$ massa específica da madeira a $0 \%$

$\rho_{12}=$ massa específica da madeira a $12 \%$

\section{Determinacão dos valores médios da massa específica por árvore}

A partir dos valores das massas específicas obtidas em cada posição i= 1,2,3 e 4, determinou-se a massa específica média ponderada por árvore, utilizando-se a equação 5 .

$$
\rho_{m}=\frac{\sum_{i=4}^{4} m_{i} * \rho_{i}}{\sum_{i=1}^{4} m_{i}}
$$

Sendo:

$\rho_{\mathrm{m}}-$ massa específica média ponderada por árvore; $\mathrm{g} / \mathrm{cm}^{3}$,

$\mathrm{m}_{\mathrm{i}}$ - massa do disco nas posições 1,2,3 e 4; e,

$\rho_{\mathrm{i}}$ - massa específica do disco na posição 1,2,3 e 4; g/cm³ (REZENDE, 1997). 


\section{Fonte radioativa e deteccão da radiação gama}

Como emissor de radiação gama foi utilizada uma fonte ${ }^{241} \mathrm{Am}$ de atividade de $200 \mathrm{mCi}$, sendo usado o fotopico de 59,6 Kev, com intensidade de emissão de $35,9 \%$. Após levantamento do espectro de emissão do ${ }^{241} \mathrm{Am}$, foi escolhida a largura da janela do contador, sendo fixada em $42 \mathrm{Kev}$ para o discriminador inferior e $84 \mathrm{Kev}$ para o discriminador superior. A detecção da radiação gama foi feita através de um cintilador sólido de duas polegadas na forma cilíndrica de $\mathrm{NaI}(\mathrm{Tl})$. O cintilador foi acoplado a uma fotomultiplicadora e os impulsos produzidos foram analisados por um monocanal. As amostras de madeira foram movimentadas perpendicularmente ao feixe de radiação gama através de um sistema móvel utilizando-se de um motor e uma fonte reguladora de voltagem. O sistema de colimação foi feito utilizando-se chumbo revestido com aço inox, permitindo uma abertura de $6 \mathrm{~mm}$ por $0,5 \mathrm{~mm}$ na saída da fonte e também na entrada do detetor.

\section{RESULTADOS E DISCUSSÃO}

Os valores da massa específica no sentido radial para as árvores 1 a 7 e para cada posição 1, 2, 3 e 4 são mostrados na Tabela 1 . Esses resultados mostram as variações da massa específica com a distância radial a $0,3 \mathrm{~m}$ de altura (base das árvores). Os resultados obtidos em outras posições, embora tenham sido considerados no contexto geral, não estão incluídos no presente trabalho. Nas Figuras 1 a 7 são mostradas de forma bem clara as variações referentes aos picos de alta massa específica correspondentes aos lenhos tardios, e os de baixa massa específica correspondentes aos lenhos iniciais. Esta é uma característica marcante para o gênero Pinus uma vez que esta espécie é bastante susceptível as variações climáticas anuais. 
Tabela 1 - Valores da massa do disco e da massa específica para as posições 1,2,3 e 4 de Pinus oocarpa.

Table 1 - Specific mass and disc mass values for the 1,2,3 and 4 position of Pinus oocarpa

\begin{tabular}{c|c|c|c|c|c|c|c|c|c}
\hline \multirow{2}{*}{$\begin{array}{c}\text { Árvore/ } \\
\text { posição }\end{array}$} & \multicolumn{2}{|c|}{ base } & \multicolumn{2}{c|}{$0,25 \mathrm{x}$ hc } & \multicolumn{2}{c|}{$0,5 \mathrm{x}$ hc } & \multicolumn{2}{c|}{$0,75 \mathrm{x}$ hc } & \multirow{2}{*}{ média } \\
\cline { 2 - 10 } & $\mathrm{g}$ & $\mathrm{g} / \mathrm{cm}^{3}$ & $\mathrm{~g}$ & $\mathrm{~g} / \mathrm{cm}^{3}$ & $\mathrm{~g}$ & $\mathrm{~g} / \mathrm{cm}^{3}$ & $\mathrm{~g}$ & $\mathrm{~g} / \mathrm{cm}^{3}$ & $\mathrm{~g} / \mathrm{cm}^{3}$ \\
\hline 1 & 2191 & 0,564 & 1052 & 0,507 & 801 & 0,508 & 294 & 0,472 & 0,533 \\
\hline 2 & 1643 & 0,578 & 1120 & 0,563 & 681 & 0,484 & 511 & 0,573 & 0,556 \\
\hline 3 & 2208 & 0,591 & 788 & 0,518 & 1165 & 0,511 & 489 & 0,482 & 0,547 \\
\hline 4 & 1511 & 0,585 & 810 & 0,531 & 799 & 0,539 & 487 & 0,527 & 0,554 \\
\hline 5 & 1340 & 0,540 & 739 & 0,546 & 626 & 0,505 & 436 & 0,496 & 0,528 \\
\hline 6 & 1276 & 0,636 & 975 & 0,653 & 1236 & 0,627 & 348 & 0,657 & 0,639 \\
\hline 7 & 1604 & 0,596 & 1313 & 0,615 & 456 & 0,497 & 232 & 0,535 & 0,585 \\
\hline média & 1632 & 0,584 & 971 & 0,562 & 823 & 0,524 & 403 & 0,534 & 0,564 \\
\hline
\end{tabular}

hc - altura comercial da árvore

Estes valores mostram que houve uma redução da massa específica com a posição relativa à altura da árvore. Conforme já descrito por outros autores (PANSHIN e DE ZEEW, 1970; BARRICHELO et al., 1983).

Para a aplicação da técnica, recomenda-se uma série de precauções como: aferir a estabilidade do aparelho durante todo o processo de análise; utilizar valores precisos para espessura da amostra em cada milímetro; procurar fazer as análises numa umidade próxima à umidade de equilíbrio; fazer corretamente as correções e conversões para a massa específica. 
Figuras 1 a 7 - Valores para massa específica, em $\mathrm{g} / \mathrm{cm}^{3}$, em função da distância radial, em milímetros, respectivamente para 7 árvores de Pinus oocarpa., sendo: $\mathrm{R}$ o coeficiente de correlação e SD o desvio padrão

Figures 1 to 7 - Specific mass values, in $\mathrm{g} / \mathrm{cm}^{3}$, based in the radial distance, in millimeters, respectively for 7 Pinus oocarpa trees, where: $R$ is the correlation coefficient and $S D$ the standard deviation

\section{Figura 1}

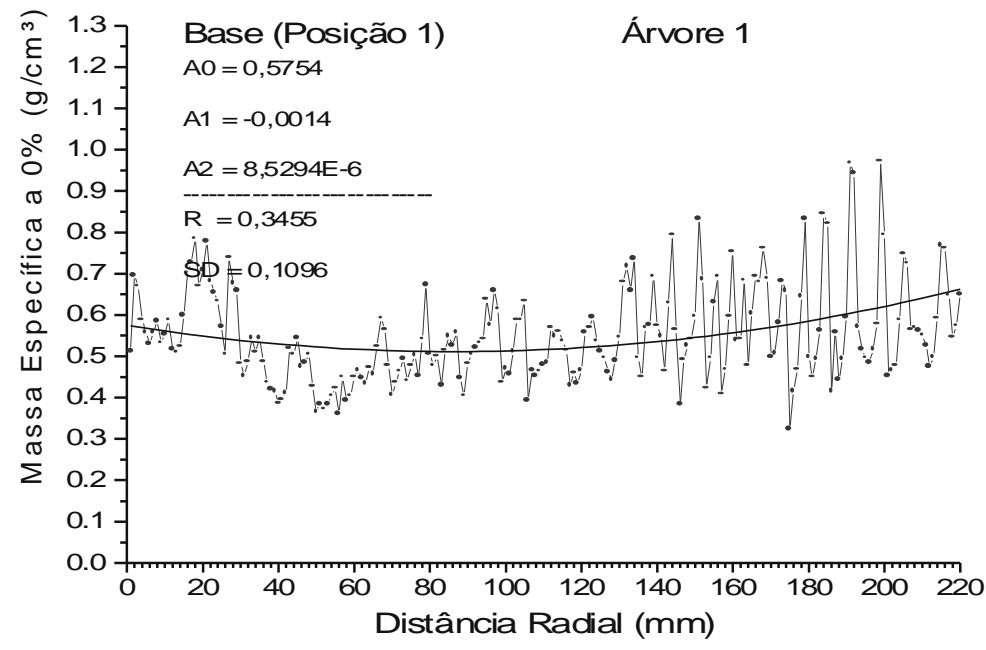


Figura 2

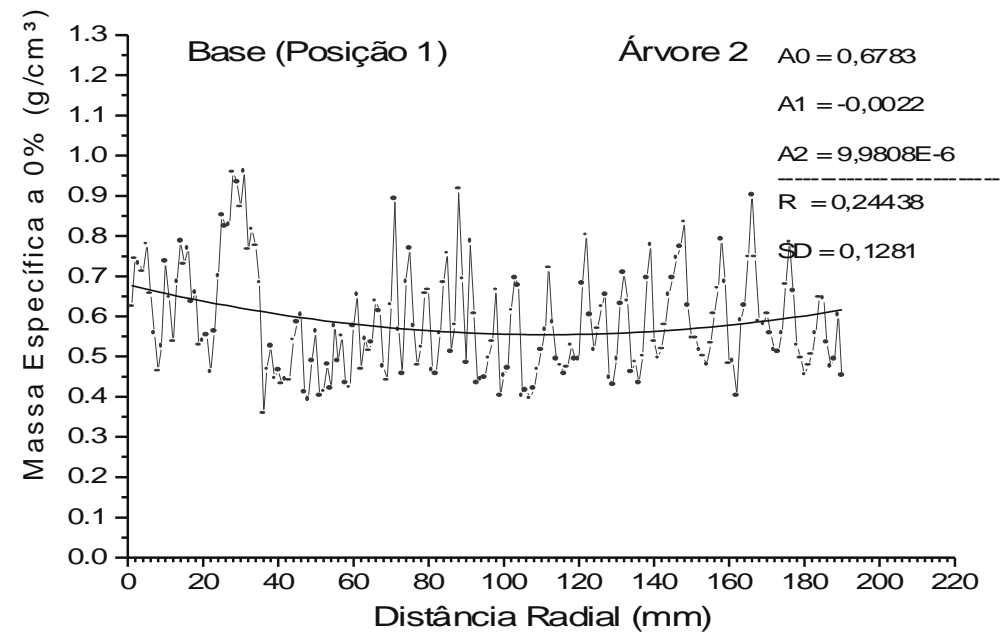

Figura 3

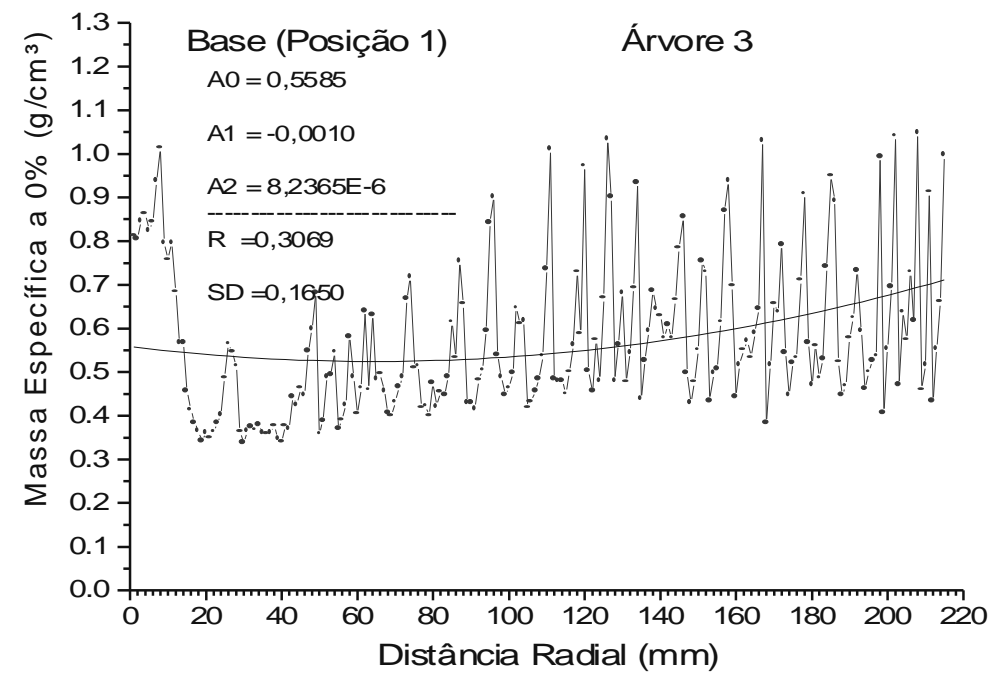


Figura 4

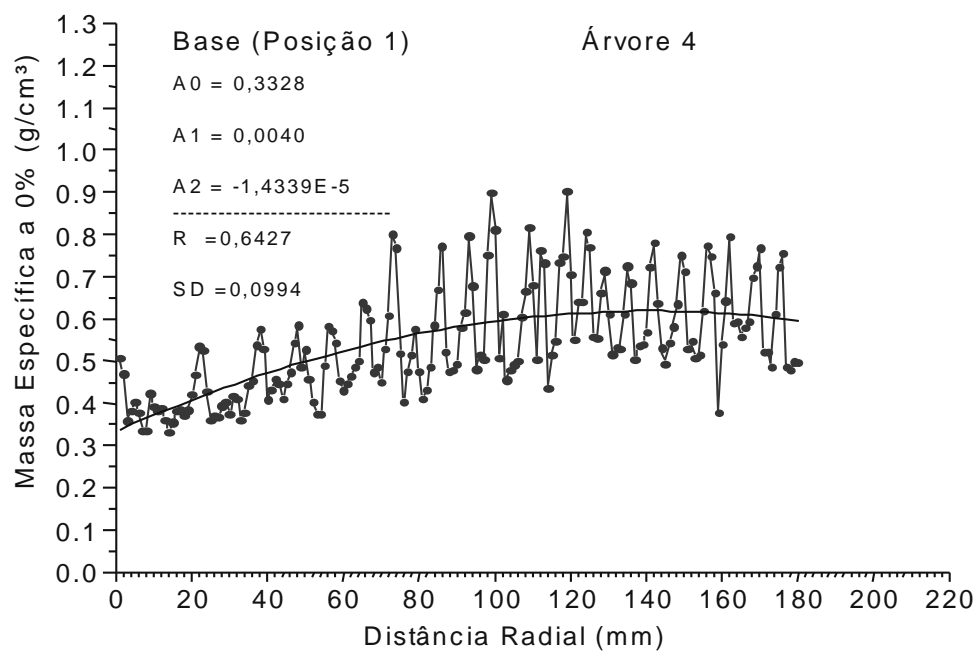

Figura 5

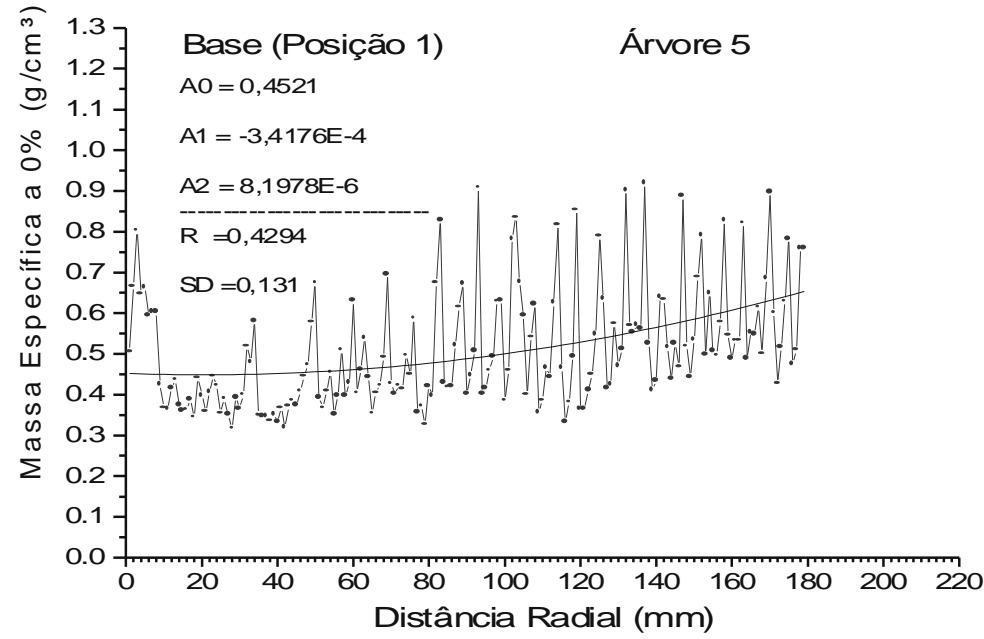


Figura 6

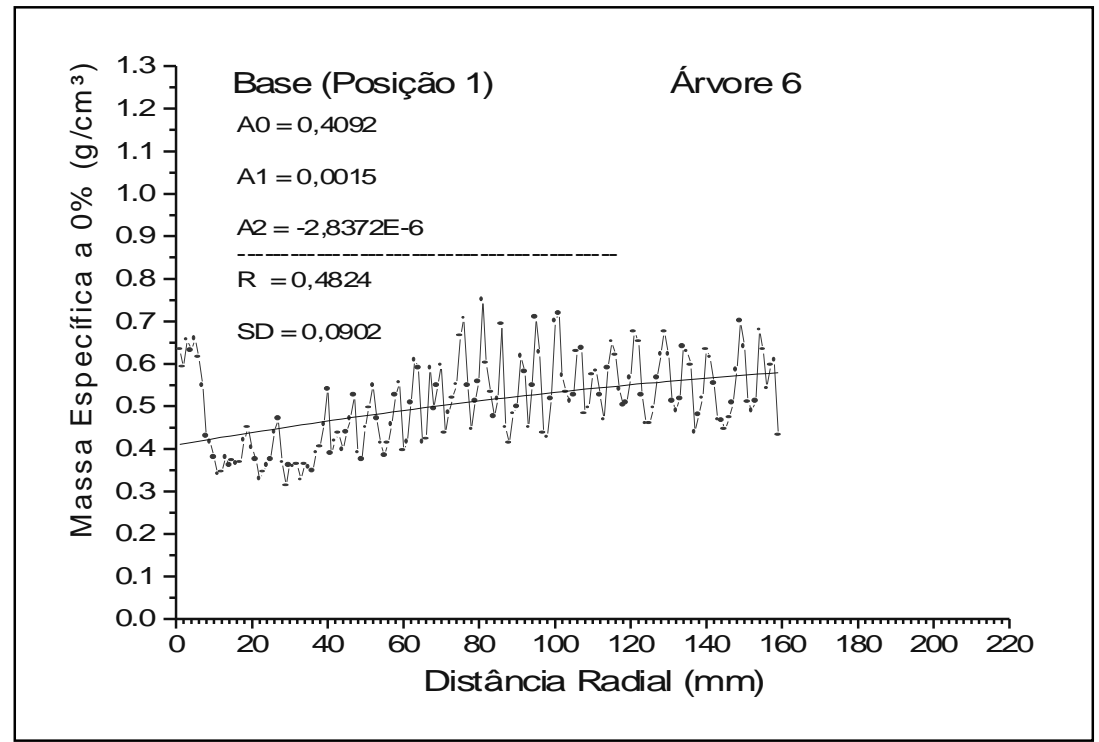

Figura 7

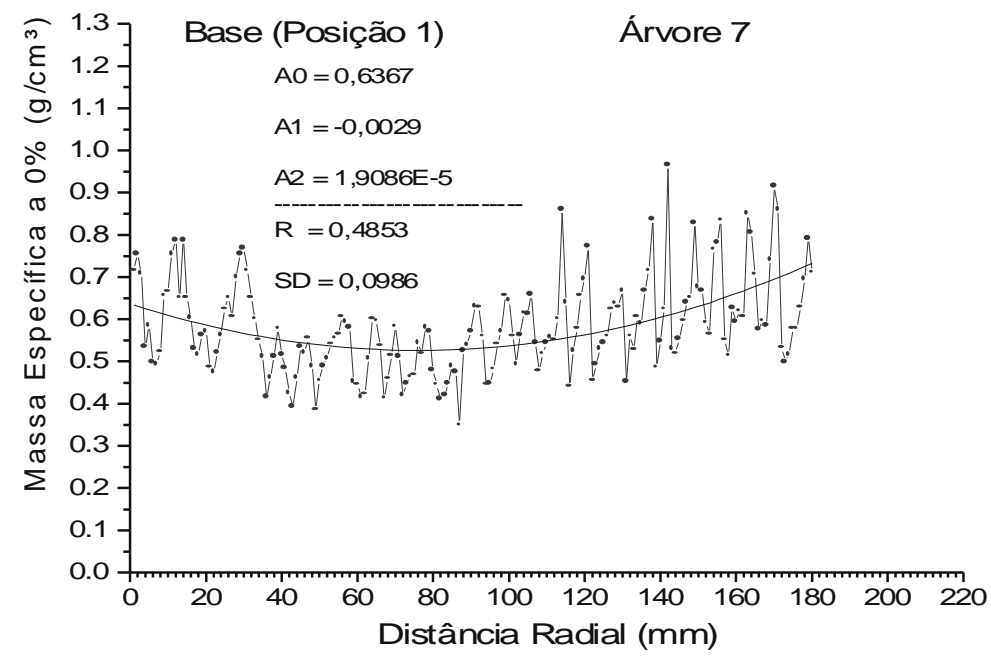


Conforme pode ser observado nas Figuras de 1 a 7, os valores baixos encontrados para $\mathrm{R}$, significam grandes variações da massa específica entre lenhos tardio e inicial, mostrando a grande sensibilidade do gênero Pinus aos fatores externos e, principalmente, aos climáticos. Essa diferença na massa específica entre lenho inicial e tardio exerce uma considerável influência na qualidade da madeira. Pois madeiras que apresentam grandes variações na massa específica estão mais propensas aos defeitos, inerentes à contração, durante à secagem.

Nota-se ainda uma grande variabilidade entre árvores dentro do mesmo povoamento. Por exemplo, as árvores 4, 6 e 7, parecem não terem sofrido tanto as variações climáticas quanto as outras, principalmente comparada com as árvores 3 e 5 (Figura 3 e Figura. 5, respectivamente).

As Figuras de 8 a 14 mostram os valores médios da massa específica em função da idade, obtidos pela análise dos anéis de crescimento, considerando as posições relativas 1, 2, 3 e 4. Os resultados mostraram, de uma maneira geral, uma massa específica crescente com a idade, até o $24^{\circ}$ ano. No entanto, algumas árvores tiveram um comportamento diferenciado das demais, principalmente por apresentarem um decréscimo da sua massa específica no início do crescimento até uma idade próxima ao $4^{\circ}$ ano. Esse resultado segundo UPRICHARD (1971) e LLROYD (1978) pode ser atribuído aos altos teores de extrativos encontrados nos primeiros anéis de crescimento localizados próximo à medula em madeira de Pinus. Esses autores enfatizam que este alto nível de resina encontrado é devido ao processo de enriquecimento com extrativo via canais resiníferos transversais. Essa característica foi evidenciada nas árvores 1 , 2, 3, 5 e 7 (Figuras. 8, 9, 10, 12 e 14).

Portanto, houve um crescimento da massa específica em função da idade até o $24^{\circ}$ ano para sete árvores estudas. A estabilização poderá ocorrer para idades bem superiores, acima de 30 anos. Entretanto, é importante lembrar que estes valores de idade são variáveis já que existe uma dependência clara e evidente da massa específica com os fatores climáticos e edáficos.

Essas considerações enfatizam a importância da técnica de atenuação da radiação gama nestes estudos, que, comprovadamente, oferece detalhes não alcançados pelos métodos tradicionais.

A técnica de atenuação da radiação gama do ${ }^{241} \mathrm{Am}$ permitiu observar com clareza as grandes variações da massa específica entre amostras, árvores e povoamento, evidenciando a importância em se estabelecer critérios seguros de amostragem para a massa específica. 
Figuras 8 a 14 - Variação da massa específica, em g/ $\mathrm{cm}^{3}$, em função da idade para as 7 árvores de Pinus oocarpa

Figure 8 to 14 - Specific mass variation, in $\mathrm{g} / \mathrm{cm}^{3}$, based in the age for the 7 Pinus oocarpa trees

Figura 8

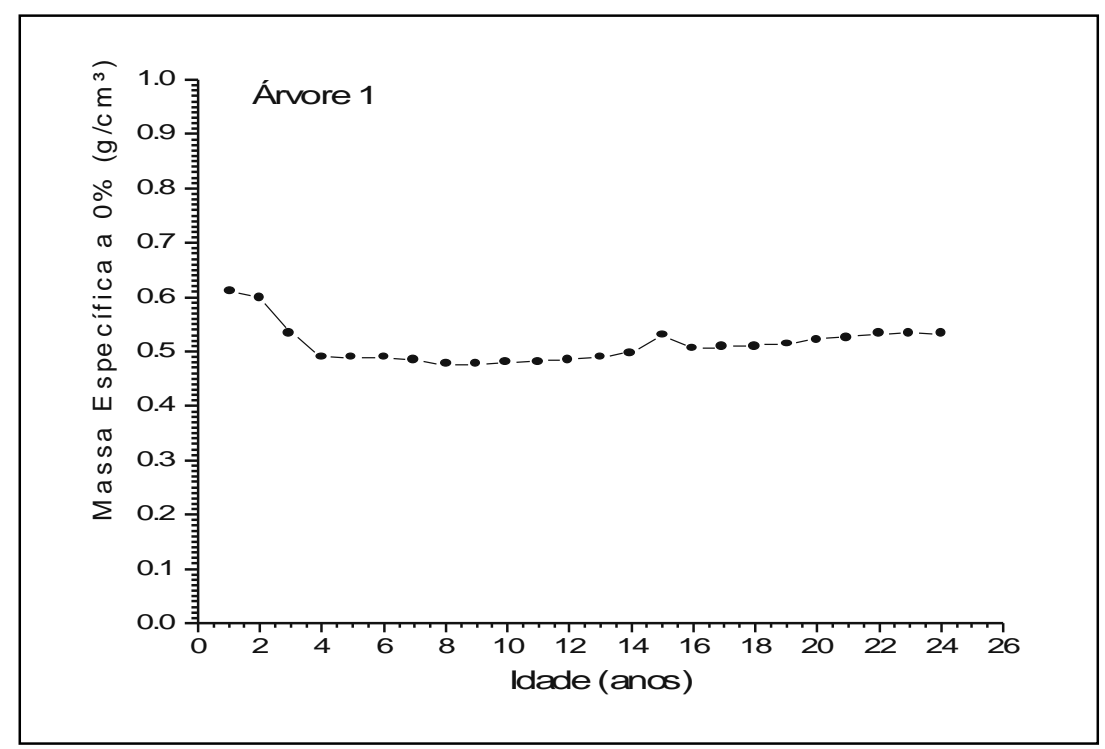

Figura 9

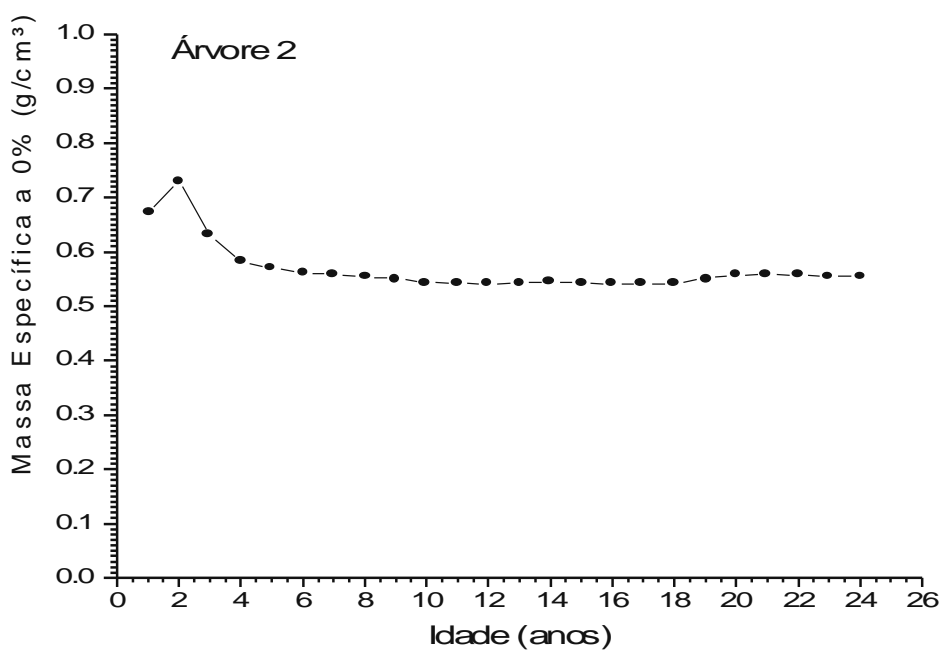


Figura 10

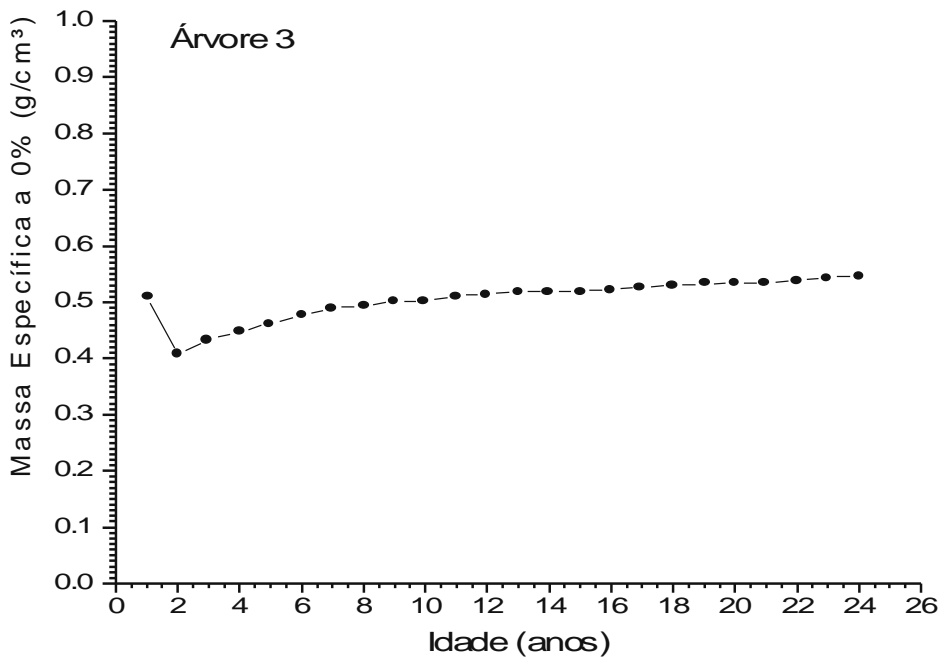

Figura 11

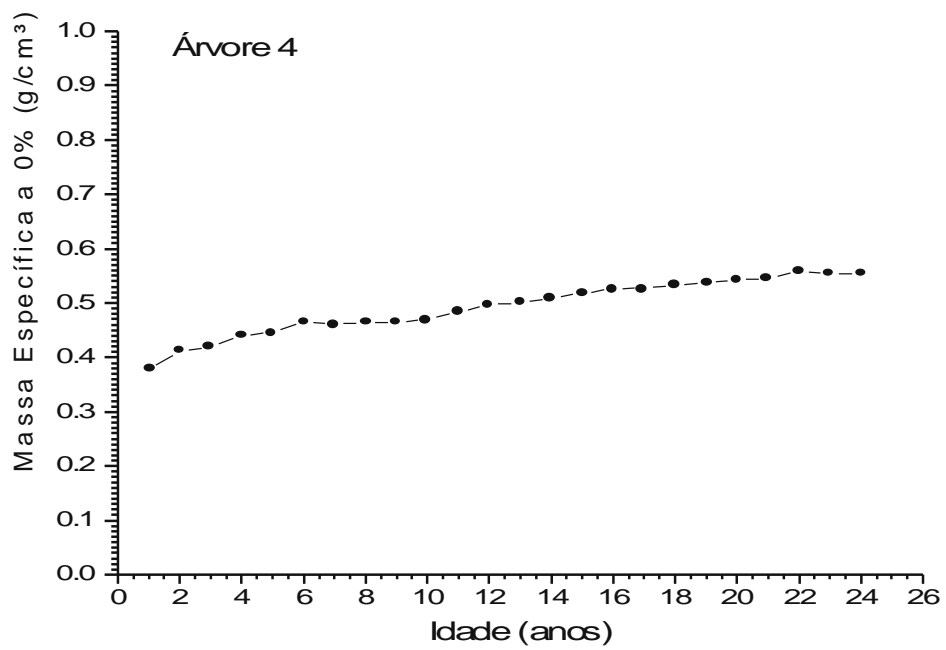


Figura 12

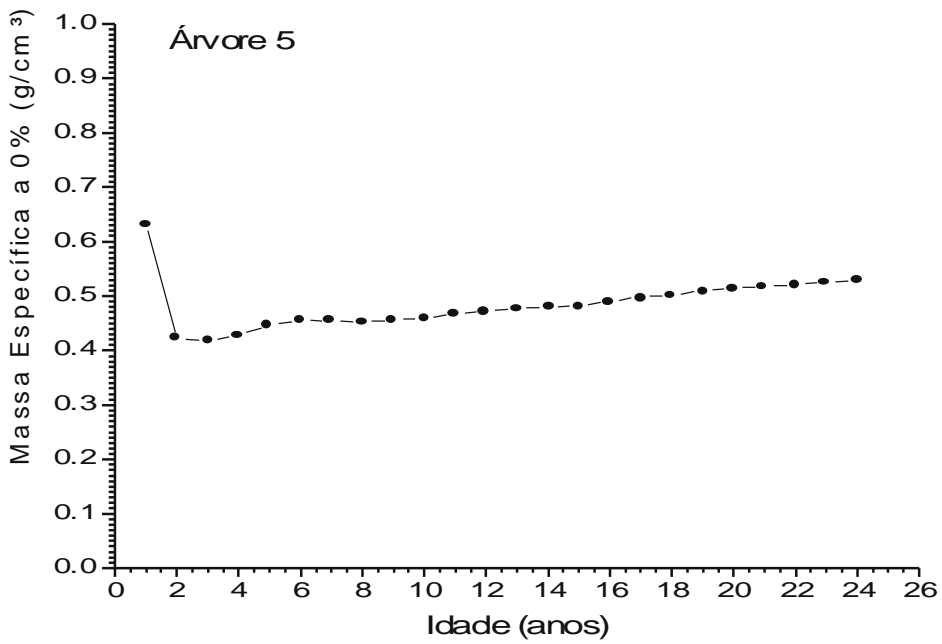

Figura 13

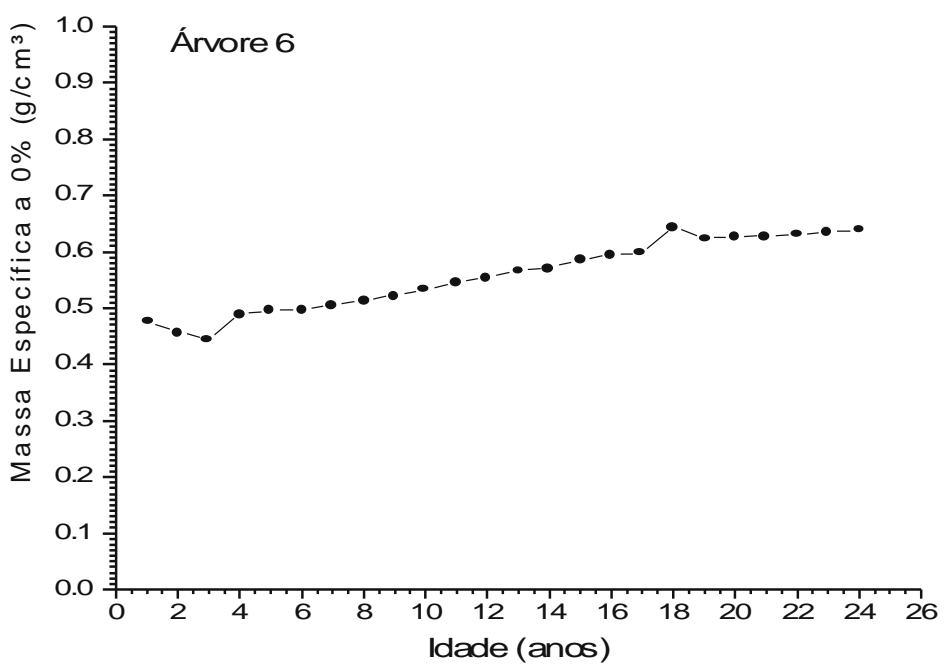


Figura 14

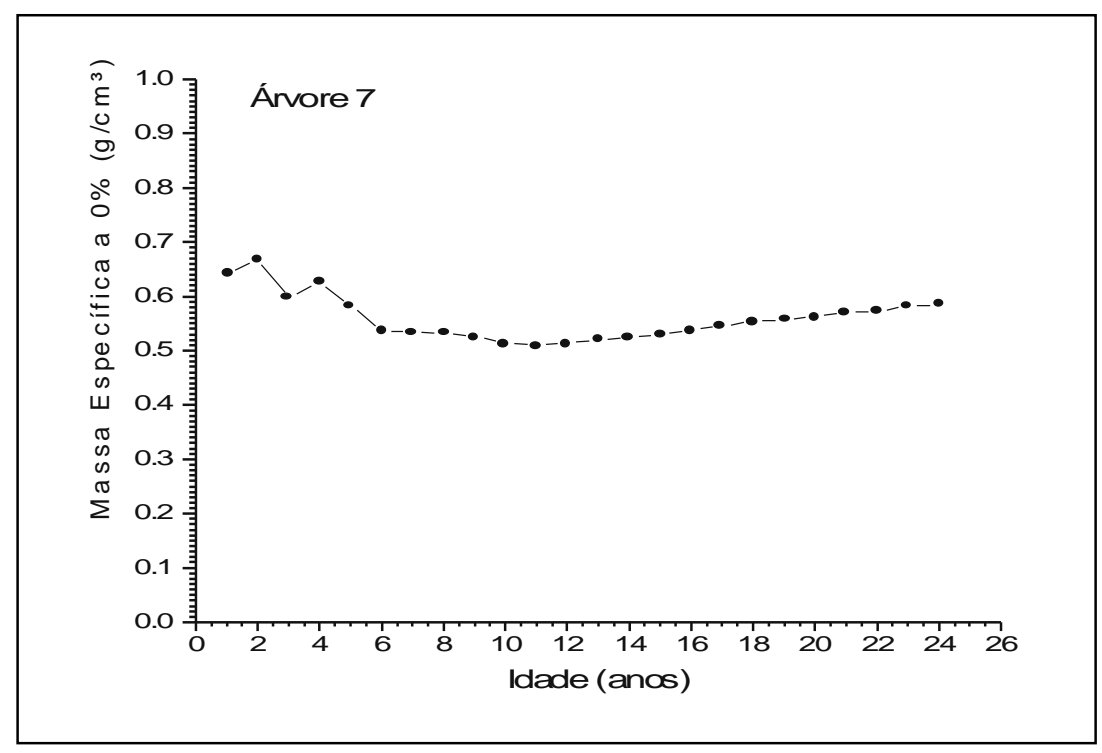

\section{CONCLUSÕES}

Os resultados permitiram concluir, para o Pinus oocarpa, que houve um aumento da massa específica no sentido radial, e com a idade, até a data do corte efetuada aos 24 anos.

Os valores encontrados para a média da massa específica, em $\mathrm{g} / \mathrm{cm}^{3}$, desta espécie nas posições relativas à altura comercial da árvore (base, 25\%, $50 \%$ e 75\%) mostraram sua redução com a altura da árvore, sendo respectivamente 0,$58 ; 0,56 ; 0,52$ e 0,53 .

A análise dos anéis de crescimento mostrou uma grande variação na massa específica entre o lenho inicial e tardio, evidenciando uma grande sensibilidade desta espécie aos fatores edáficos e climáticos.

A análise dos anéis de crescimento auxiliada pela técnica de atenuação da radiação gama do ${ }^{241}$ Am mostrou-se prática e vantajosa nos estudos do comportamento da massa específica. Principalmente por apresentar medidas pontuais, ótima precisão e rapidez na obtenção dos resultados. 


\section{BIBLIOGRAFIA CITADA}

BARRICHELO, L.E.G.; BRITO, J.O; MIGLIORINI, A.J. Estudo da variação da densidade básica em Eucalyptus spp. In: CONGRESSO FLORESTAL Brasileiro, $4^{\circ}$, Belo Horizonte, 1982. Anais...São Paulo, SBS, 1983, p. 726731.

FERRAZ, E.S.B. \& MORTATTI, J. Determining density of wood by gamma ray attenuation method. Growth ring identification. Wood Microden Bull. vol. 2, p 26-33, 1982.

FERRAZ, E.S.B. Determinação da densidade da madeira por atenuação gama de baixa energia. Bol. IPEF (Instituto de Pesquisa e Estudos Florestais). vol. 12, p. 61-8, 1976.

LLYD, J.A. Distribution of extractives in Pinus radiata earlywood and latewood. NZJ. For. Sci., 8 (2), 288 - 94. 1978.

PANSHIN, A.T.; DE ZEEUW, C. Textbook of Wood Technology. New York, MC Graw-Hill Book, 1970 ed. 705p.

REZENDE, M.A. Estudo dos anéis de crescimento de duas variedades de Pinus caribeia cultivados na Bahia para produtividade, massa específica e nutrição mineral. Piracicaba, 1987. 144 p. Tese (Doutorado) - Escola Superior de Agricultura Luiz de Queiroz, Universidade de São Paulo.

REZENDE, M.A. Uma abordagem não convencional sobre as principais características físicas da madeira, com ênfase para retratibilidade, massa específica e técnica de atenuação da radiação gama. Tese de Livre Docência em Física para Engenharia Florestal. Universidade Estadual Paulista - Júlio de Mesquita Filho - Campus de Botucatu, 1997, 138p.

REZENDE, M.A., SAGLIETTI, J.R.C. \& GUERRINI, I.A. Estudo das interrelações entre massa específica, retratibilidade e umidade da madeira do Pinus oocarpa var. hondurensis aos 8 anos de idade. IPEF (Instituto de Pesquisa e Estudos Florestais). vol. 48-9, p. 133-41, 1995.

REZENDE, M.A.; SAGLIETTI, J.R. Variação da massa específica da madeira de Eucalyptus grandis aos 8 anos de idade em função de diferentes níveis de produtividade. Scientia Florestalis, 53, 1998. Piracicaba - SP.

TROVATTI. L.R. Resposta da densidade dos anéis de crescimento de Pinus oocarpa Schiedi aos fatores climáticos. Piracicaba, 1982. 97 p. Dissertação (Mestrado) - Escola Superior de Agricultura Luiz de Queiroz, Universidade de São Paulo.

SEVERO, E. T. D. Estudo sobre o efeito da vaporização nas propriedades e comportamento de secagem da madeira de Eucalyptus dunnii Maid. Curitiba, 1998, 200p. Tese (Doutoramento em Ciências Florestais), Setor de Ciências Agrárias, Universidade Federal do Paraná. 
UPRICHARD, J.M. Cellulose and lignin content in Pinus radiata D. Don: within-tree variation in chemical composition, density and tracheid length. Holzforschung, 24 (4), 97-105. 1971.

\section{AGRADECIMENTOS}

- Fundação de Amparo à Pesquisa do Estado de São Paulo - FAPESP (Proc. 89/1109-5 e 94/5023-6);

- Fundação para o desenvolvimento da Unesp - FUNDUNESP ( Proc. 448/99 DFP)

- Empresa Duraflora S.A. 